\title{
RPG Guardiões: desenvolvendo a produção textual através da escrita criativa
}

\author{
Luciano da Silva Rodrigues ${ }^{1}$, Greyce da Silva Rodrigues ${ }^{1}$, Bruna da Silva Santos ${ }^{1}$, \\ Silvia de Castro Bertagnolli ${ }^{1}$, Marcelo Augusto Rauh Schmitt ${ }^{1}$, Josiane Carolina \\ Soares Ramos Procasko ${ }^{1}$ \\ ${ }^{1}$ Instituto Federal de Educação, Ciência e Tecnologia do Rio Grande do Sul (IFRS) \\ 90.030-041 - Porto Alegre - RS - Brasil \\ \{lucianodsradm, greycempie\}@gmail.com, oba_santos@hotmail.com, \\ \{silvia.bertagnolli, marcelo.schmitt, josiane.ramos\}@poa.ifrs.edu.br
}

\begin{abstract}
This paper presents an RPG game called Guardiões that promotes textual production through creative writing. In order to carry out such investigation a bibliographic research and a case study were conducted. Data were collected from the produced texts and from quizzes. The game used was about environment and students created stories related to ecology problems in a ludic and contextualized way. Results indicate that interdisciplinary was favored by the game and that students' engagement was amplified because playing leverages learning and creativity.
\end{abstract}

Resumo. Este artigo apresenta o jogo no estilo RPG, denominado Guardiões, que incentiva a produção textual através da escrita criativa. Para o desenvolvimento da investigação, foram utilizados os procedimentos de pesquisa bibliográfica e estudo de caso, sendo que a coleta de dados teve como fontes as produções textuais e os questionários respondidos pelos participantes. $O$ jogo explorou a temática do meio ambiente, de modo que os estudantes elaboraram histórias relacionadas com problemas ambientais de forma lúdica e contextualizada. Os resultados apontam que a interdisciplinaridade foi favorecida através do jogo e que o engajamento dos estudantes foi ampliado, visto que o lúdico potencializa a aprendizagem e a criatividade.

\section{Introdução}

O convívio em sociedade exige uma boa comunicação entre os sujeitos. Esta comunicação é necessária para que se efetive uma interação saudável no desenvolvimento de direitos e deveres civis, políticos e sociais. Uma das formas de expressão de informações, pensamentos e sentimentos mais utilizadas é a palavra escrita. Entre outras produções, utilizam-se cartas, livros, revistas, documentos legais, mensagens eletrônicas. Assim, as habilidades referentes à linguagem escrita são fundamentais para o exercício da cidadania [Brasil 2017].

Com base nessa premissa, entende-se que a escola deva contribuir na formação das pessoas elaborando estratégias para auxiliar no desenvolvimento de habilidades e competências de produção textual. Embora a habilidade da escrita seja extremamente necessária, as notas médias de redação dos alunos brasileiros no Exame Nacional do 
Ensino Médio (ENEM) tiveram uma queda de 35,76 pontos no ano de 2018 em relação a 2017 [Inep 2019]. Embora a queda não pareça expressiva, a produção textual deve receber uma atenção significativa pois permite "refletir sobre diferentes contextos e situações sociais" [Brasil 2017], além de possibilitar o posicionamento do sujeito como autor e produtor de conhecimento. Várias estratégias pedagógicas podem ser utilizadas para a produção textual. Da mesma forma que os jogos são utilizados para o desenvolvimento de diversos conteúdos curriculares [Huizinga 1993; Prensky 2001], acredita-se que lacunas relativas à produção textual também possam ser mitigadas com o uso deste tipo de artefato.

Existem diversos gêneros de jogos: ação, tiro, corrida, luta, aventura, açãoaventura, simulação, estratégia, RPG (Role Playing Games), entre outros [Schuytema 2008; Novak, 2010], que podem auxiliar nos processos de ensino e aprendizagem. No contexto deste trabalho, optou-se por utilizar o gênero RPG, pois ele promove a construção de narrativas e a interpretação de papéis, podendo ser jogado em equipe, para fomentar também habilidades sociais. Como argumentam Pessoa et al. (2019), esse estilo de jogo incentiva a "...cooperação entre os participantes, não existem perdedores nem excluídos. Todos participam do início ao fim ...”. Além disso, segundo Bittencourt e Giraffa (2003), o jogo de RPG pode ser utilizado na escola para fins pedagógicos, já que potencializam a criatividade, o lúdico, empatia entre os participantes e a criação coletiva de textos.

Desta forma, a questão norteadora delimitada para essa pesquisa compreende a seguinte questão. "Como um jogo do gênero RPG pode fomentar a produção textual e a escrita criativa?" Para responder esse questionamento, percebeu-se que a temática abordada pelo jogo deve ser o elemento central, pois o engajamento dos estudantes é maior quando eles possuem interesse pelo assunto e ele está vinculado ao seu dia a dia. Outro ponto importante diz respeito ao critério da interdisciplinaridade e da contextualização, estabelecidos nas Diretrizes Curriculares Nacionais da Educação Básica (DCNs) [Brasil 2013], que estabelece que o currículo deve propiciar “... a interlocução entre os diferentes campos do conhecimento e a transversalidade do conhecimento de diferentes disciplinas, bem como o estudo e o desenvolvimento de projetos referidos a temas concretos da realidade dos estudantes".

Para conduzir o estudo, foi realizada uma pesquisa bibliográfica, combinada com estudos exploratórios, que culminaram com um estudo de caso. Este último item foi conduzido através de uma prática pedagógica voltada para a produção textual coletiva, desenvolvida com 44 alunos matriculados do Ensino Fundamental II e no Ensino Médio de escolas públicas do Rio Grande do Sul, os quais estavam participando de oficinas temáticas no $1^{\circ}$ Festival de Invenção e Criatividade do Rio Grande do Sul (FIC/RS), organizado pelo Núcleo Porto Alegre da Rede Brasileira de Aprendizagem Criativa (RBAC) e que é vinculado ao Instituto Federal de Educação, Ciência e Tecnologia do Rio Grande do Sul - IFRS.

O jogo educacional de RPG, livre e gratuito, denominado "Guardiões", tem como intuito potencializar o aprendizado de forma lúdica e criativa a respeito da produção textual partindo da seguinte situação problema: "O meio ambiente foi atacado. Sua missão é salvar esse mundo fantástico!". O jogo aborda a temática do meio ambiente por se tratar de um assunto interdisciplinar e por estar presente no cotidiano dos estudantes. 
A definição do nome "Guardiões" tem como objetivo despertar os estudantes para a questão de proteger, preservar e zelar pelo planeta.

Este artigo prossegue apresentando, nas seções 2 e 3, alguns aspectos teóricos e trabalhos relacionados. A seção 4 expõem os procedimentos metodológicos empregados na elaboração deste trabalho. A seção 5 descreve como é possível jogar o RPG. Os resultados e discussões são abordados na seção 6. Por fim, são expostas as conclusões relacionadas com a presente investigação.

\section{Jogos de RPG: Estratégias no Contexto Educacional}

Para Huizinga [1993], todas as culturas possuem jogos individuais e coletivos que promovem descontração e lazer. São passados de geração em geração e são reinventados de acordo com características geográficas e temporais, mantendo fatores universais como prazer, ludicidade e imaginação. Atualmente, existe uma vasta pesquisa sobre o uso de jogos educacionais e sobre a forma como podem ser utilizados em estratégias de ensino e de aprendizagem. Neste contexto, os RPGs podem ser explorados de forma digital ou não digital, oferecendo aos professores oportunidades para abordar competências e habilidades orientadas pela Base Nacional Comum Curricular - BNCC [Brasil 2017] e em consonância com as DCNs [Brasil 2013].

Os jogos de RPG têm como característica principal a possibilidade da interpretação de papéis. Na maioria das vezes ele é jogado em grupo e cada jogador interpreta o seu personagem. Nesse estilo de jogo, um jogador realiza o papel de mestre, ou seja, um narrador que conta a história a ser vivida pelos personagens, avaliando os resultados das ações ou rolagens de dados efetuadas pelos demais jogadores. Jackson (1996) contribui definindo o RPG como: "Um role playing game é um jogo onde cada participante faz o papel de um personagem, tomando parte em uma aventura imaginária".

Como no RPG os jogadores interpretam papéis de seus personagens em um mundo fictício [Peterson 2012; Dormans 2006], é possível que os cenários e os personagens dos jogos possam ser adaptados para abordar os mais diversos conteúdos curriculares. No contexto nacional, cabem ressaltar os estudos de Cezar et al. (2019), Ferreira Junior et al. (2017) e Rosetti Junior et al. (2015), os quais descrevem que tais jogos auxiliam a construção de aprendizagens por meio da ludicidade, fator que fomenta o engajamento dos alunos quanto aos conteúdos desenvolvidos. Esses autores utilizam o RPG para auxiliar no ensino da área da matemática em disciplinas de cálculo de cursos de graduação e sistema monetário para alunos de Ensino Fundamental. Dentre as produções científicas a respeito da utilização do RPG na educação, podem ser citados os estudos internacionais de Mellado et al. (2018), Wu et al. (2016) e Lee, et al. (2014) que testaram a potencialidade pedagógica da interpretação de papéis no desenvolvimento de trabalho em equipe, resolução de problemas e estímulo à imaginação.

\section{Aprendizagem Criativa e RPG}

O maior compromisso das instituições de ensino é com a aprendizagem dos seus estudantes e, desta forma, muitas escolas concentram seus esforços e intencionalidades na construção ou ressignificação de estratégias com foco no interesse dos discentes. Também é tarefa da educação formal atuar sobre algumas das necessidades da sociedade do século XXI, como o desenvolvimento de pessoas criativas, flexíveis e produtoras de inovação [Resnick 2017]. Neste intuito, os princípios da aprendizagem criativa oferecem 
possibilidades para as tarefas educacionais propondo quatro estratégias: (i) projeto planejar para colocar em prática as ideias; (ii) paixão - temática que vai mobilizar os esforços programados de forma significativa ao sujeito; (iii) pares - construção de conhecimento através de trabalho em equipe; e, (iv) pensar brincando - desenvolvimento de brincadeiras que resultem em experiências de aprendizagem [Resnick 2017].

Os jogos de RPG colaboram com a aprendizagem criativa, pois podem ser utilizados como ferramenta metodológica para auxiliar o desenvolvimento de criação de projetos e trabalho em equipe através de ludicidade. Assim, os jogos de RPG podem estimular a produção textual como orienta BNCC, já que o ensino de Língua Portuguesa necessita buscar "práticas de linguagem já vivenciadas pelos jovens para a ampliação dessas práticas, em direção a novas experiências" [Brasil 2017], para a aquisição de competências e habilidades com relação à escrita. As DCNs ainda estabelecem que os currículos devem estabelecer estratégias para "a promoção da aprendizagem criativa como processo de sistematização dos conhecimentos elaborados, como caminho pedagógico de superação à mera memorização". Desta forma, o uso e domínio da linguagem escrita vai além do aprendizado de regras e normas, pois através desta linguagem os alunos manifestam desejos e angústias, interagem com outras perspectivas e culturas, refletem e posicionam-se frente a problemas sociais que atingem a sua realidade cotidiana.

\section{Materiais e Métodos}

A natureza da pesquisa é aplicada uma vez que tem como pretensão produzir conhecimento para aplicação prática em sala de aula [Prodanov and Freitas 2013]. Com objetivo exploratório visou a obter maiores informações sobre o uso do RPG no desenvolvimento de produção textual dos alunos e sobre como esse gênero pode favorecer a escrita criativa. Os procedimentos metodológicos contaram com pesquisa bibliográfica e estudo de caso [Prodanov and Freitas 2013; Gil 2008]. Com o primeiro foi possível identificar vários aspectos teóricos que o jogo deveria abordar. Já o estudo de caso compreendeu o uso do jogo educacional por 44 alunos do Ensino Fundamental II e Ensino Médio de escolas públicas do Rio Grande do Sul no $1^{\circ}$ Festival de Invenção e Criatividade do Rio Grande do Sul (FIC/RS), realizado em 2019. O desenvolvimento do RPG levou em consideração alguns dos elementos teóricos que foram estudados durante a pesquisa bibliográfica [Schuytema 2008; Novak 2010] e que se encontram detalhados nos próximos parágrafos.

A definição do jogo começou pela identificação da temática, que consiste na seleção do ponto norteador do jogo. Para isso, levaram-se em consideração alguns temas presentes na BNCC, sendo que se optou pela temática do meio ambiente, pois assim seria possível articular, além da escrita, outras áreas do conhecimento. A partir dessa delimitação inicial, foi selecionado o gênero do jogo. Para a definição do roteiro optouse pelo gênero de RPG, uma vez que propicia ao estudante trabalhar em grupo, planejar, construir de forma colaborativa o texto, comunicar, interpretar e simular papéis, bem como resolver problemas. Ao concluir essas etapas, começou-se com a definição do roteiro, a qual foi pautado pela estrutura do jogo Dominus. O sistema Dominus foi escolhido para ser adaptado por ser gratuito, de licença aberta, capacidade de trabalhar temas genéricos, poucas regras e ter um design simples [Dominus 2019]. O sistema encontra-se dividido em quatro dimensões: trama, personagens ou arquétipos, cenas e o 
banco de ideias, como ilustra a Figura 1. Os elementos adotados em cada uma das quatro dimensões tiveram por base a temática selecionada.

\section{GUARDIÕES}

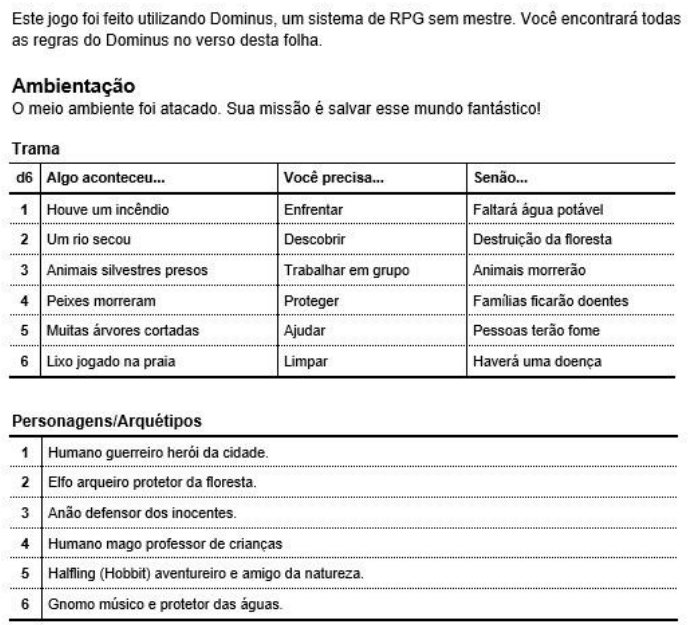

\begin{tabular}{|c|c|c|c|c|}
\hline d6 & Lugares & \multicolumn{2}{|c|}{ Encontros (1-3) } & Eventos (4-6) \\
\hline 1 & Cidade & \multicolumn{2}{|c|}{ Pescador } & Insetos atacam uma vila \\
\hline 2 & Desertio & \multicolumn{2}{|l|}{ Guarda } & O Viläo suja a cidade \\
\hline 3 & Praia & \multicolumn{2}{|l|}{ Criança } & Caçadores prendem animais \\
\hline 4 & Estrada & \multicolumn{2}{|c|}{ Sábio bondoso } & Goblins poluem um rio \\
\hline 5 & Floresta & \multicolumn{2}{|c|}{ Camponês } & Orcs destroem floresta \\
\hline 6 & Castelo & \multicolumn{2}{|c|}{ Aventureiro aposentado } & Um Dragão queimou a floresta \\
\hline \multicolumn{5}{|c|}{ Banco de Ideias } \\
\hline d6 & Assunto & Ação & Coisa & Qualidade \\
\hline 1 & Plantas ficam doentes & Encontrar & Mapa secreto & Amigo \\
\hline 2 & Pássaros desaparecem & Escrever & Livro mágico & Valioso \\
\hline 3 & Uma missão & Prender & Chave & Poluente \\
\hline 4 & Escondido na floresta & Buscar & Pergaminho misterio & Assustador \\
\hline 5 & Atividade ilegal & Investigar & Espada brilhante & Mágico \\
\hline 6 & Eles fizeram & Libertar & Baú do tesouro & Amaldiçoado \\
\hline
\end{tabular}

Figura 1. Guardiões: as 4 dimensões do RPG

A seguir, foi realizada a contextualização do jogo, que também considera a temática e as dimensões prévias. Além disso, adota um conjunto de regras (Figura 2) que estabelece o encadeamento das ações que os estudantes devem realizar. Por exemplo, a "Regra 1: Preparação" guia o início do jogo, já a "Regra - X3" incentiva a construção de um artefato que utilize massa de modelar caseira (a massa pode ser confeccionada com os alunos antes do jogo) e outros materiais recicláveis com o objetivo de materializar o significado que a produção textual trouxe para as equipes.

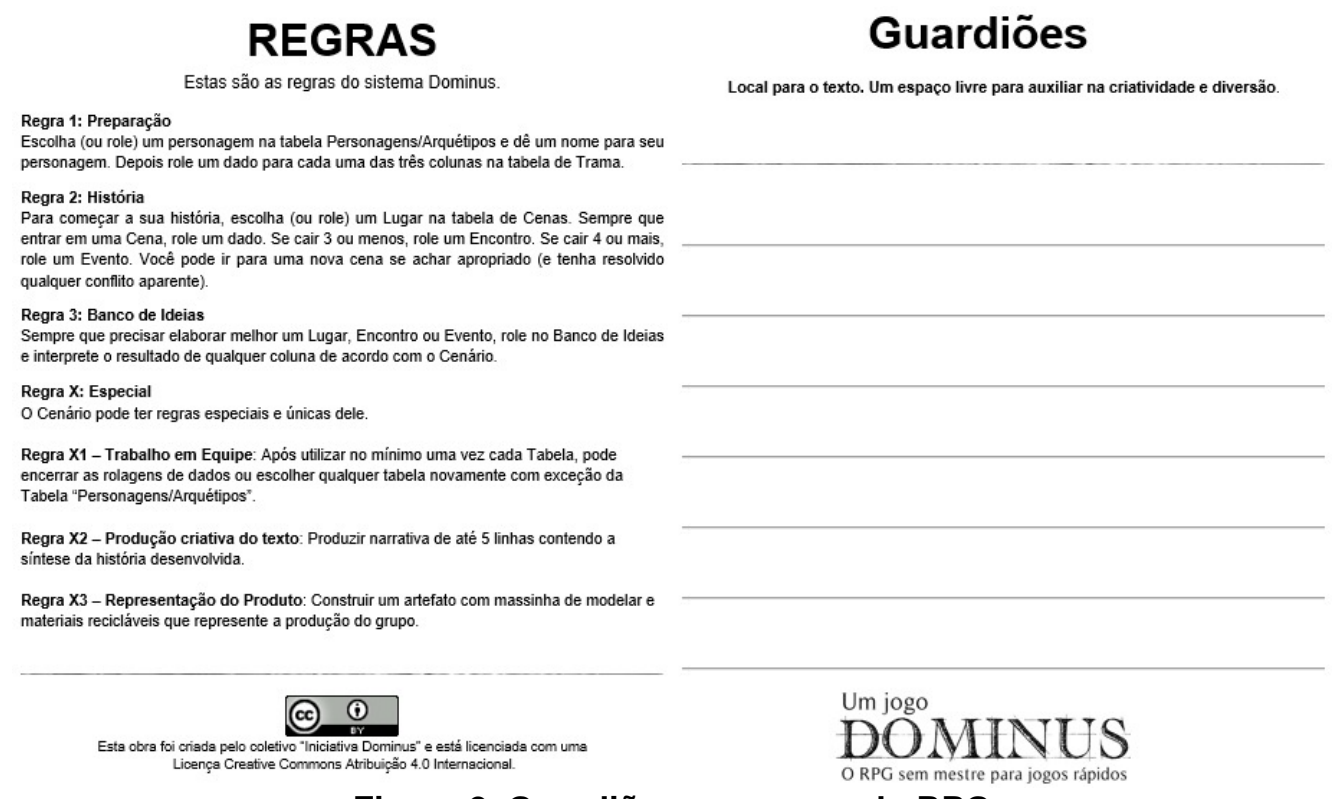

Figura 2. Guardiões: as regras do RPG

Assim, o jogo incentiva os alunos na criação de um texto de forma colaborativa e alinhada com a temática exposta pelo professor e interliga outros conhecimentos de modo que o aluno perceba que "todo conhecimento mantém um diálogo permanente com outros conhecimentos" [Brasil 2013]. Para a produção do jogo, foram utilizados papel e caneta visto que a ideia do jogo é incentivar a escrita criativa de uma forma não digital. Também 
se utilizou massa de modelar caseira e outros materiais recicláveis que têm o objetivo de materializar e representar o significado que a produção textual trouxe para o grupo de estudantes.

Por fim, foi realizada a avaliação inicial do jogo que possibilitou identificar quais ajustes deveriam ser realizados e o quanto ele favoreceu a produção textual criativa. Para fazer essa avaliação, foi realizada uma coleta de dados usando a produção textual construída em grupo por meio do jogo de RPG apresentado e também foi produzido um questionário avaliativo sobre a atividade proposta, o qual foi respondido individualmente pelos alunos. A análise dos dados coletados foi realizada através de explicação textual clara e objetiva proposta por Prodanov e Freitas (2013).

\section{Guardiões: jogo educacional de interpretação de papéis}

Para utilizar o jogo de RPG proposto, o professor, ou mestre de jogo, divide a turma em grupos pequenos e aborda a temática selecionada, contextualizando-a e apresentando os saberes que devem ser desenvolvidos. É necessário explicar aos alunos que o jogo é baseado na interpretação de papéis e que a história a ser construída deve ser jogada em grupo. Também é importante deixar claro que a estratégia tem como foco a construção do seu aprendizado. Os grupos devem representar papéis dos arquétipos do jogo (ver Figura 1 - Dimensão Personagens/Arquétipos) - humano guerreiro herói da cidade, elfo arqueiro protetor da floresta, anão defensor dos inocentes, humano mago professor de crianças, halfling (Hobbit) aventureiro e amigo da natureza, gnomo músico e protetor das águas - a fim de construir narrativa a respeito de suas características sobre a preservação da natureza.

Após esta breve introdução aos alunos jogadores, o professor deve utilizar a tabela chamada "Personagens/Arquétipos" na qual escolhe, usando dados em conjunto com cada grupo, qual personagem será jogado. Um dado de seis faces é "rolado" para que haja um efeito de aleatoriedade para a definição do personagem central. É importante ressaltar que todas as dimensões (Figura 1) estão atreladas ao número de lados do dado de seis faces. Assim, para a escolha do personagem, o grupo deve "rolar" o dado. Se o número aleatório for o número 1, o grupo escolhe o personagem da linha 1 e vai jogar com o arquétipo "Humano guerreiro herói da cidade". No próximo passo o dado é usado para definir a dimensão "Trama". O dado deve ser rolado três vezes: uma para indicar qual linha o grupo deverá usar na coluna "Algo aconteceu"; a segunda rolagem de dado indica a opção da coluna "Você precisa..."; e a terceira rolagem de dados indica uma das linhas da coluna "Senão". Por exemplo, se o resultado das rolagens para a "Trama" for a sequência: 2, 2 e 6, os alunos têm a seguinte informação: "um rio secou, os personagens devem descobrir senão haverá uma doença”.

Ao definir a trama central é necessário iniciar a dimensão "Cena". O primeiro valor obtido com o dado é para definir o local onde a trama se desenvolverá; e o segundo valor "rolado" pelo dado vai determinar se o personagem vai encontrar alguém (neste caso o valor do dado deve estar entre 1 e 3), usando a coluna "Encontro"; ou se acontecerá algo (valor de 4 a 6 no dado), relacionando com a coluna "Evento". Destaca-se que a dimensão "Banco de ideias" deve ser utilizada apenas se o professor achar necessário ou caso os alunos apresentem dificuldades em realizar a sua produção textual. Recomendase o uso do dado também para essa dimensão do jogo, visando a manter o efeito da aleatoriedade e desafiar ainda mais a imaginação do grupo, para potencializar a narrativa. 
Sugere-se que o jogo deva encerrar quando o grupo tiver utilizado pelo menos uma vez cada dimensão. Mas o professor tem total autonomia para concluir quando julgar adequado.

Ao término da atividade, cada grupo de alunos terá realizado uma produção textual, sendo que o professor terá anotado todas as informações das dimensões relativas a cada grupo, buscando identificar como cada dimensão contribuiu para a produção. Essa produção fica registrada em papel. Nesta pesquisa, além da produção realizada, os estudantes foram convidados a responder um questionário com oito perguntas, onde avaliaram o jogo Guardiões. A próxima seção apresenta os resultados obtidos com a primeira experimentação prática do jogo.

\section{Resultados e Discussões}

Inicialmente, os alunos foram convidados a jogar o RPG, sendo que tanto a temática quanto a estratégia de aplicação foram contextualizadas para os estudantes. Ao concluir o jogo, cada grupo de estudantes havia produzido um texto de forma criativa, encadeando os personagens, tramas, cenas, os quais foram sorteados de forma aleatória. Assim como trata o PeaceMaker [Ferreira et al. 2017], abordando a resolução de conflitos e questões vinculadas à paz, no jogo Guardiões os alunos foram organizados em grupos, onde todos construíram a narrativa de acordo com o tema "meio ambiente". Pode-se perceber que essa organização em equipes fomentou as discussões e deu mais liberdade de criação para os estudantes durante o desenvolvimento da atividade.

Ao término da produção textual, os estudantes foram convidados para responder um questionário, o qual foi aplicado com todos os participantes, e cujas respostas encontram-se ilustradas na Figura 3. Ao questionar se o participante já havia jogado RPG previamente, $56,8 \%$ responderam que não conheciam ou não tinham experiência com jogos deste gênero. Após a experiência proporcionada aos alunos, foi questionado se eles gostariam de jogar RPG em sua escola: $86 \%$ dos alunos que conheceram o jogo Guardiões afirmaram que gostariam de jogar RPG no ambiente escolar, assim evidenciando o potencial motivador do RPG para a educação. Isso confirma o que argumentam Wu et al. (2016) e Bittencourt e Giraffa (2003) em suas pesquisas, o potencial pedagógico do jogo RPG na educação. Esses dados demonstram ainda que, como a maioria dos jogos aplicados no ambiente educacional concentram-se em modelos mais tradicionais, o RPG pode ser uma alternativa para que o estudante possa desenvolver outras aprendizagens, tais como "... argumentar e relatar fatos oralmente, em sequência temporal e causal, organizando e adequando sua fala ao contexto em que é produzida. Ouvir, compreender, contar, recontar e criar narrativas." [Brasil 2017]. Durante a realização da atividade, percebeu-se que os alunos discutiram bastante sobre o tema e que a interpretação de papéis acabou incentivando o engajamento e proporcionando maior criatividade na execução das tarefas pedagógicas, conforme já argumentavam Cézar et al (2019).

Na aplicação do RPG Guardiões identificou-se uma limitação: o reduzido nível de conhecimento sobre os RPGs. Como 56,8\% dos jogadores não conheciam jogos de RPG, alguns participantes apresentaram dificuldade em entender a sua proposta no início. Acredita-se que as orientações introdutórias da atividade devam ser apoiadas em um exemplo que simule a narrativa, para facilitar a compreensão por parte dos alunos.

Ao questionar os estudantes sobre a experiência de jogar com os colegas, a maioria apontou como uma experiência positiva. Para Huizinga (1993), o jogo permite a 
representação de alguma coisa. No caso da criança, ela representa um papel de um personagem como um ator realiza no teatro, algo diferente da sua realidade. Logo, o aluno sente prazer ao imaginar e poder criar a sua própria história jogando RPG com os colegas, interpretando um personagem. Este contexto pode estimular a produção de uma narrativa em grupo. Além disso, o aluno percebe-se como produtor de conhecimento e autor de uma história, o que também está articulado à BNCC, que define que os estudantes devam experimentar no ambiente escolar diferentes papéis para desenvolver novos saberes.

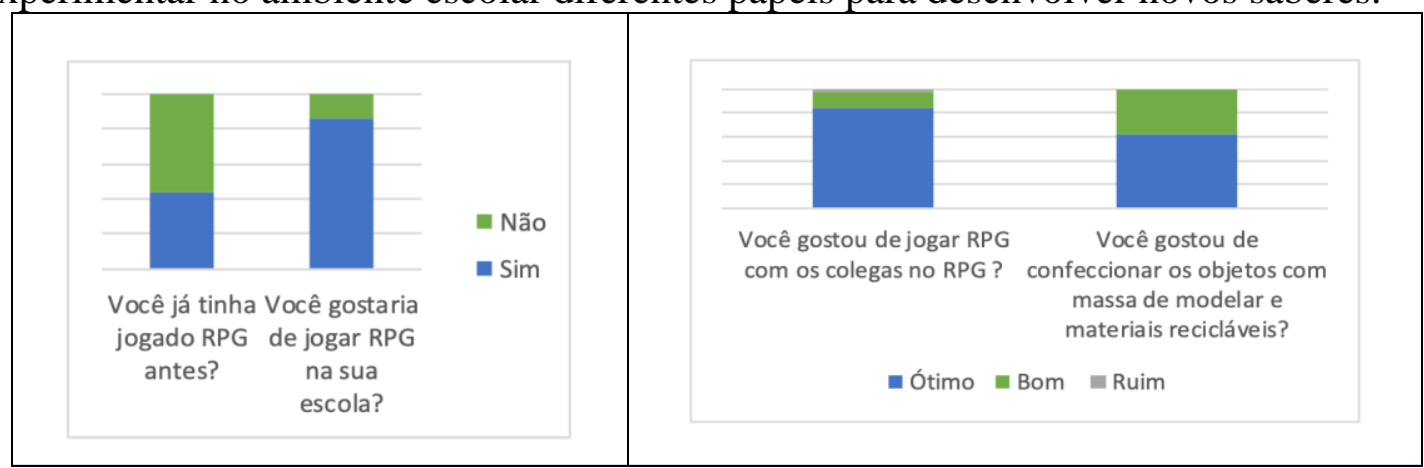

Figura 3. Guardiões: respostas do questionário de avaliação

As rolagens de dados para as escolhas de personagens, trama e cena constaram em todos os textos elaborados, logo o jogo influenciou diretamente o contexto da narrativa. Nos textos, foi percebido que o fator da aleatoriedade teve influência direta e instigou a criatividade dos alunos, uma vez que alguns grupos escolheram mais opções na dimensão "Banco de ideias" para desenvolver soluções mais elaboradas, aumentando também o desafio de manter lógica entre a partida jogada com um texto alinhado ao tema proposto. Com base no trabalho de Rosseti et al. (2015), percebeu-se que o uso do jogo poderia explorar atividades desplugadas, visto que naquele trabalho "os alunos registram os cálculos no papel e o docente coletará os modelos de resolução das questões para discutir a variedade de caminhos que se percorre para encontrar o resultado". Assim, de forma semelhante, no Guardiões, os textos desenvolvidos durante a dinâmica e após o jogo foram analisados por uma docente Licenciada em Letras e uma pedagoga. Isso permitiu identificar que os estudantes seguiram a aleatoriedade estabelecida pela rolagem dos dados.

Após a entrega da produção textual realizada pelos alunos, eles ainda estavam envolvidos com o jogo Guardiões, pois seguiram a "Regra - X3". Assim cada grupo construiu um artefato utilizando materiais recicláveis e massa de modelar caseira para representar a narrativa construída. Então, além de proporcionar engajamento dos participantes para a realização da criação de texto, o jogo Guardiões oportunizou o contato com a reutilização de materiais que iriam para o lixo, desencadeando diálogos e reflexões sobre a temática de preservação do meio ambiente. Ao serem questionados sobre a construção do artefato utilizando os materiais disponíveis, todos os participantes apontaram como positiva esta ação. Tal satisfação reforçou a possibilidade de proporcionar a aprendizagem criativa [Resnick 2017], pois através dos artefatos criados eles expuseram a identidade do seu grupo e a representação concreta da narrativa desenvolvida.

Através da leitura das narrativas, foi observado que os alunos criaram soluções para problemas ligados à degradação do meio ambiente em seus textos de acordo com os resultados das rolagens de dados, sendo este um dos desafios propostos pelo jogo. Outro ponto que merece destaque é a percepção que os estudantes demonstraram que os 
conteúdos das diferentes disciplinas estão interligados. Todos perceberam a importância de saber escrever, pois a compreensão da produção que estava sendo gerada ficava prejudicada com textos com imprecisões linguísticas. Eles identificaram que, em algumas situações, as ciências se ligam à geografia e à matemática. Assim, pode-se afirmar que o jogo proposto possibilitou "contextualizar os conteúdos dos componentes curriculares, identificando estratégias para apresentá-los, representá-los, exemplificá-los, conectá-los e torná-los significativos, com base na realidade do lugar e do tempo nos quais as aprendizagens estão situadas" [Brasil 2017]. Ainda conforme Mellado et al. (2018), o uso de RPGs nas diversas áreas do conhecimento é promissor, visto que pode ser usado como ferramenta para explorar a escrita criativa e a leitura. E o uso dessa estratégia pedagógica pode tornar o processo de aprendizagem mais atrativo para os estudantes [Lee et al. 2014], em especial os do nível fundamental.

\section{Conclusões}

Ao longo do processo de investigação e escrita do presente artigo, conclui-se que o objetivo de propor um jogo educacional que utiliza o potencial do RPG para incentivar a produção textual, com foco na aprendizagem criativa, foi atingido. Este dado é confirmado pelas narrativas produzidas sobre a temática do meio ambiente, as quais mantêm ligação direta com os seus personagens interpretados dentro do jogo. Além disso, durante a observação da atividade, a qual foi realizada pelos docentes envolvidos, percebeu-se que diversas habilidades podem ser desenvolvidas com o jogo no estilo RPG que foi desenvolvido: a criatividade, a resolução de problemas, o trabalho em equipe, $o$ raciocínio lógico e o fortalecimento de relações interpessoais.

Destaca-se ainda que a proposta pedagógica desenvolvida pode ser replicada em outros contextos educacionais, uma vez que os recursos necessários para jogar são de fácil acesso. Além disso, a facilidade de adaptar o jogo (modificando a trama, personagens ou arquétipos, cenas e o banco de ideias) para outros contextos pode ser vista como um instrumento que tem o potencial de abordar competências e habilidades estabelecidas pela BNCC. Cabe, também, ao professor usar de criatividade para adaptar a estrutura do jogo, de modo que ele possa ser adotado como prática pedagógica a outros conteúdos.

\section{Referências}

Bittencourt, J. R. and Giraffa, L. M. (2003) "A Utilização dos Role-Playing Games Digitais no Processo de Ensino-Aprendizagem”, PUCRS, http://www.pucrs.br/facinprov/wp-content/uploads/sites/19/2016/03/tr031.pdf.

Brasil. Ministério da Educação. (2013) "Diretrizes Curriculares Nacionais Gerais da Educação Básica", http://portal.mec.gov.br/index.php?option=com_docman\&view=download\&alias=13 448-diretrizes-curiculares-nacionais-2013-pdf\&Itemid=30192.

Brasil. Ministério da Educação. (2017) "Base Nacional Comum Curricular", http://basenacionalcomum.mec.gov.br/wp-content/uploads/2018/02/bncc-20dezsite.pdf.

Cezar, V.; Garcia, P.; Botelho, V. and Miletto, E. M. (2019) "Towards an RPG Game to Teach Calculus", In: IEEE International Conference on Advanced Learning Technologies. 
IX Congresso Brasileiro de Informática na Educação (CBIE 2020)

Anais do XXXI Simpósio Brasileiro de Informática na Educação (SBIE 2020)

Dominus. (2019) "Dominus: o RPG sem mestre para jogos rápidos", https://arquivorpg.com.br/dominus/.

Dormans, J. (2006) "On the role of the die: a brief ludologic study of pen-and-paper roleplaying games and their rules", In: Game Studies, The International Journal of Computer Game Research, v. 6, n. 1, http://gamestudies.org/0601/articles/dormans.

Ferreira Junior, S. A.; Pacheco, M. G.; Silveira Junior, C. R. and Barra, A. S. B. (2017) "Metodologias de uso de jogo computacional RPG em sala de aula: estudo de caso com o jogo PeaceMaker", RENOTE, Porto Alegre, v. 15, n. 1, jul. 2017.

Gil, A. C. (2008) "Métodos e técnicas de pesquisa social”, 6. ed., Atlas.

Huizinga, J. (1993) "Homo Ludens: o jogo como elemento da cultura”, Perspectiva.

Inep. (2019) “Sinopse Estatísticas do Exame Nacional de Ensino Médio 2018”, Brasília: Inep, http://portal.inep.gov.br/web/guest/sinopses-estatisticas-do-enem.

Jackson, S. (1996) “GURPS Basic Set. Generic Universal Role Playing System”, 3. ed., Steve Jackson Games.

Lee, G. H.; Talib, A. Z.; Zainon, W. M. N. W. and Lim, C. K. (2014) "Learning History Using Role-Playing Game (RPG) on Mobile Platform”, In: Jeong H., S. Obaidat M., Yen N., Park J. (eds) Advances in Computer Science and its Applications. vol. 279.

Mellado, R.; Melgarejo, B.; Cubillos, C.; Roncagliolo, S. and Gonzalez, N. (2018) "Role video game tool for teaching myths and legends to school basic students", In: International Conference of the Chilean Computer Science Society.

Novak, J. (2010) “Desenvolvimento de games", 2. ed. Cengage Learning.

Pessoa, M.; Oliveira, D. F.; Carvalho, L. G.; Oliveira, E. H. T.; Nakamura, W. and Conte, T. (2019) "CodePlay: Uma Plataforma de Gamificação baseada em Jogos de RPG Multiplayer”, In: Simpósio Brasileiro de Informática na Educação.

Peterson, J. (2012) "Playing at the world: A history of simulating wars, people and fantastic adventures, from chess to role-playing games", Unreason.

Prensky, M. (2001) “Digital Natives, Digital Immigrants Part 1", On the Horizon. v. 9, n. 5, Out, https://www.marcprensky.com/writing/Prensky\%20\%20Digital\%20Natives,\%20Digital\%20Immigrants\%20-\%20Part1.pdf.

Prodanov, C. C. and Freitas, E. C. (2013) "Metodologia do trabalho científico: métodos e técnicas da pesquisa e do trabalho acadêmico", Feevale.

Resnick, M. (2017) "Lifelong Kindergarten: Cultivating Creativity Through Projects, Passion, Peers, and Play", MIT Press.

Rosetti Junior, H.; Amaral, G. P.; Schimiguel, J.; Martins, C. A. and Araújo Junior, C. F. (2015) "O jogo na educação matemática: desenvolvimento de um RPG para trabalhar o conceito de moeda no ensino fundamental", In: HOLOS'15, ano 31, v. 8. 2015.

Schuytema, P. (2008) "Design de games: uma abordagem prática”, Cengage Learning.

Wu, W. H., Yan, W. C., Kao, H. Y., Wang, W. Y., and Wu, Y.C. J. (2016) "Integration of RPG use and ELC foundation to examine students' learning for practice", In: Computers in Human Behavior. v. 55. 